\title{
Early predictive factors for postoperative pancreatic fistula after distal pancreatectomy for pancreatic cancer: A retrospective study
}

Masahiro Fukada ( $\nabla$ flyhighvb@yahoo.co.jp )

Gifu University Hospital

Katsutoshi Murase

Gifu University Hospital

Toshiya Higashi

Gifu University Hospital

Ryoma Yokoi

Gifu University Hospital

Yoshihiro Tanaka

Gifu University Hospital

Naoki Okumura

Gifu University Hospital

Nobuhisa Matsuhashi

Gifu University Hospital

Takao Takahashi

Gifu University Hospital

Kazuhiro Yoshida

Gifu University Hospital

\section{Research Article}

Keywords: Signal intensity ratio on T1-weighted MRI, pancreatic cancer, postoperative pancreatic fistula, distal pancreatectomy

Posted Date: February 4th, 2022

DOI: https://doi.org/10.21203/rs.3.rs-1252385/v1

License: (1) (1) This work is licensed under a Creative Commons Attribution 4.0 International License.

Read Full License 


\section{Abstract}

Background: Postoperative pancreatic fistula (POPF) is the most serious complication of distal pancreatectomy (DP). When POPF occurs and becomes severe, it causes secondary complications and leads to a longer treatment period. Therefore, especially for pancreatic cancer (PC), POPF may have a negative impact on not only short-term outcomes, but also on postoperative treatment. This study aimed to identify early predictive factors of POPF after DP for PC.

Methods: This retrospective, single-institution study comprised of 55 patients with PC who underwent DP (excluding simultaneous resection of other organs and other pancreatic diseases) between January 2010 and December 2021 at the Gifu University Hospital. We statistically analyzed pre, intra-, and postoperative 23 factors to identify early predictive factors for POPF.

Results: According to the definition and grading of the International Study Group of Pancreatic Fistula (ISGPF), 12 (21.8\%) of 55 patients had POPF grades B and C. In the univariate analysis, POPF was significantly associated with the pancreas-to-muscle signal intensity ratio on $\mathrm{T}_{1}$-weighted magnetic resonance imaging (SIR on $\mathrm{T}_{1}-\mathrm{W} \mathrm{MRI}$ ), the drainage fluid amylase (D-Amy) level on postoperative day 3 (POD3), C-reactive protein (CRP) on POD3, and heart rate on POD3. In multivariate analysis, pancreas-tomuscle SIR on $\mathrm{T}_{1}$-W MRI (>1.37; odds ratio [OR] 17.08; 95\% confidence interval [CI] 1.64 - 598.16; $\mathrm{p}=$ 0.02), D-Amy level on POD3 (>1200 U/L; OR 20.00; 95\% Cl $1.73-563.83 ; p=0.02$ ) and heart rate on POD3 (>100 bpm; OR 15.33; $95 \% \mathrm{Cl} 1.53-258.45 ; p=0.02$ ) were identified as independent early predictive factors for POPF.

Conclusion: Preoperative pancreas-to-muscle SIR on $\mathrm{T}_{1}-\mathrm{w} \mathrm{MRI}$ and postoperative D-Amy level and heart rate significantly correlated with POPF after DP for PC. Postoperative management based on these predictive factors may contribute to shortened hospital stay and smooth introduction to postoperative treatment.

\section{Background}

Distal pancreatectomy (DP) is an established procedure for pancreatic cancer (PC) located in the body and tail of the pancreas. Although surgical techniques and perioperative management for DP have significantly improved over recent decades, the complication rate following DP remains high [1-6]. In particular, the incidence of postoperative pancreatic fistula (POPF) is high $(10 \%-60 \%)$ and the most clinically problematic complication. When POPF occurs and becomes severe, it causes postoperative bleeding, intra-abdominal abscess, delayed gastric emptying, and sepsis as secondary complications [79]. As a result, it causes not only prolonged treatment period but also surgery-related death. Furthermore, postoperative adjuvant chemotherapy is strongly recommended in the National Comprehensive Cancer Network clinical practice guidelines in oncology (NCCN Guidelines ${ }^{\circledR}$ ) for pancreatic adenocarcinoma [10]. Prolonged POPF treatment may delay the initiation of adjuvant chemotherapy and adversely affect long- 
term prognosis. Therefore, it is necessary to predict the onset of POPF and perform intervention as soon as possible.

Previous studies have reported various predictive factors for POPF after DP, such as body mass index (BMI), pancreatic thickness, pancreatic texture, intraoperative blood loss, and amylase level of drainage fluid [11-31]; however, a clear consensus has not yet been established. The objective on this study was to identify early predictive factors of POPF to shorten the hospital stay after DP for PC.

\section{Methods}

\section{Patients}

In this single-center retrospective study, we enrolled 106 consecutive patients who underwent DP at Gifu University Hospital between January 2010 and December 2021. All procedures were conducted by expert surgeons who had qualified through the board certification system of the Japanese Society of HepatoBiliary-Pancreatic Surgery (JSHBPS). We excluded 51 patients in total (tumor histopathology other than adenocarcinoma, $n=42$; simultaneous resection of other organs, $n=9$ ), and a total of 55 patients with primary PC were included in this study (Figure 1). We conducted our study in accordance with the World Medical Association Declaration of Helsinki and the study was approved by the Ethics Committee of Gifu University (approval number: 2021-026).

Patient characteristics were classified into three categories: pre-, intra-, and post-operative factors (Figure 2). First, the preoperative 11 factors were age, sex, BMI, diabetes mellitus, serum albumin level, tumor marker level (carcinoembryonic antigen [CEA] and carbohydrate antigen 19-9 [CA19-9]), preoperative chemotherapy, tumor size, tumor location, and pancreas-to-muscle signal intensity ratio on $\mathrm{T}_{1}$-weighted magnetic resonance imaging (MRI). Secondly, intraoperative 6 factors included operative time, blood loss, surgical procedure (open or laparoscopic surgery), pancreatic resection procedure (hand-sewn or stapler), pancreas texture (soft or hard), and pancreas thickness measured intraoperatively on resection site. Finally, postoperative 6 factors included the amylase levels of drainage fluid and serum (D-Amy and SAmy), the white blood cell (WBC) count, C-reactive protein (CRP) level, body temperature, and heart rate on postoperative day (POD) 1 and 3.

\section{Perioperative management}

Regarding DP for PC, regional lymph node dissection with splenectomy in accordance with the classification of pancreatic carcinoma of the Japan Pancreas Society [32], and pancreatic resection on the portal vein were performed. Pancreatic resection is performed with hand-sewn closure or using a linear stapler.

Among hand-sewn closure group, the pancreas was resected after the identification of the main pancreatic duct, and main pancreatic duct was ligated with a 3-0 silk suture. The stump of the remnant pancreas was closed with vertical mattress suture using 5-0 polypropylene. Among the group that 
underwent pancreatic resection using a linear stapler, the pancreas was resected using Endo GIA ${ }^{\text {TM }}$ TriStaple or Signia ${ }^{\mathrm{TM}}$ stapling system (Medtronic plc., Dublin, Ireland) with a purple or black cartridge. The closure jaw was clamped carefully and slowly, taking 5 minutes at a fixed speed. The firing was performed at a speed of $1 \mathrm{~cm}$ per minute by firmly fixing the stapler. After firing, the jaws of the stapler were held shut for 1 minute. One 19Fr. Blake silicon drain (Johnson and Johnson Inc. New Brunswick, NJ, US) was placed near the stump of the remnant pancreas. The drain was to be removed on POD 4-5 when the drainage fluid was clear and postoperative course could pose no problem. The D-Amy and S-Amy level were measured on POD 1, 3, and 5. All patients received prophylactic antibiotics (cefmetazole) only intraoperatively or for 2 days postoperatively.

\section{Pancreas-to-muscle signal intensity ration on $T_{1}$-weighted MRI}

Previously, we studied the potential value of preoperative MRI in evaluating pancreatic properties [33, 34] and reported that the pancreas-to-muscle signal intensity ratio on $\mathrm{T}_{1}$-weighted MRI (SIR on $\mathrm{T}_{1}$-w MRI) significantly correlated with pancreatic fibrosis, and that it may be a potential biomarker for predicting POPF. The signal intensity of the pancreatic parenchyma on the portal vein and the paraspinal muscle was measured using fat-suppressed axial $\mathrm{T}_{1}$-weighted imaging (Figure 3). The pancreas-to-muscle SIR on $\mathrm{T}_{1}$-w MRI was calculated using the following equation: [SI of the pancreatic parenchyma] / [SI of the paraspinal muscle].

\section{Definition of POPF}

In this study, we only included clinically symptomatic POPF. Therefore, only grades B and C pancreatic fistulas were defined as POPF (Grade B, symptomatic fistula requiring therapeutic intervention such as antibiotics and percutaneous drainage; Grade $\mathrm{C}$, symptomatic fistula associated with a severe general condition of patients, sepsis, and multiorgan failure requiring aggressive treatment in the intensive care unit and surgical intervention), based on International Study Group of Pancreatic Fistula (ISGPF) definitions [35]. Diagnosis day of POPF was defined as the date when intra-abdominal fluid collection with positive cultures was identified by ultra-sonography (US) or computed tomography (CT).

\section{Statistical analysis}

Continuous variables are expressed as median (range) values, and categorical variables are expressed as frequencies (percentages). For comparisons of variables between the POPF and non-POPF groups, a Fisher's exact test was used for categorical variables, and a Mann-Whitney $U$ test was used for continuous variables. The predictive ability for POPF after DP for PC was assessed by calculating the area under the receiver operating characteristic (ROC) curve. Youden's index was used to determine the optimal cut-off value to calculate both specificities and sensitivities in the ROC curve analysis. The variables identified as potentially significant by univariate analysis were selected for multivariate analysis with a logistic regression model to identify the independent predictors of POPF after DP for PC. The limit of statistical significance for all analyses was defined as a 2-sided p-value of 0.05 . All statistical analyses were performed using JMP software (SAS Institute Inc., Cary, NC, USA). 


\section{Results}

Comparison of clinical outcomes between patients with and without POPF

In total, 55 patients underwent DP for PC. Symptomatic POPF occurred in 12 (21.8 \%) patients. Patients' clinical outcomes after DP for PC are summarized in Table 1. The median time at which POPF was confirmed was POD 9 (range, 7-25 days), the median time until hospital discharge was 39 days postoperatively (range, 12-81 days), and 2 patients had died within 30 postoperative days.

A comparison between patients with and without POPF indicated that there were significant differences in postoperative death within 30 days $(p=0.01)$, hospital days $(p<0.01)$, and period until the start of postoperative adjuvant chemotherapy $(p<0.01)$.

Comparison of pre-, intra-, and post-operative status between patients with and without POPF

Table 2 shows a summary of comparison of 23 factors classified into three categories between patients with and without POPF.

First, among pre-operative factors, the pancreas-to-muscle SIR on $\mathrm{T}_{1}$-w MRI was significantly higher in the POPF group than in the non-POPF group $(p<0.01)$. Secondly, among intra-operative factors, there was no significant difference between two groups. Finally, among post-operative factors, D-Amy level on POD3, CRP level on POD3, and heart rate on POD3 were significantly higher in the POPF group than in the nonPOPF group $(0.02,0.046$, and 0.03 , respectively).

Cut-off values of SIR on $T_{1}$-W MRI, D-Amy level on POD3, and CRP levels on POD3 for predicting POPF

The ROC curves for generating cut-off values of SIR on $\mathrm{T}_{1}-\mathrm{w}$ MRI, D-Amy level on POD3, and CRP level on POD3 are shown in Figure 4. The cut-off value of SIR on $T_{1}-w$ MRI was +1.37, with an area under the curve (AUC) of 0.782 , a sensitivity of $90.0 \%$, and specificity of $66.7 \%$ (Figure $4 a$ ). The cut-off value of DAmy level on POD3 was $1206 \mathrm{U} / \mathrm{L}$, with an AUC of 0.729 , a sensitivity of $58.3 \%$, and specificity of $86.2 \%$ (Figure 4b). The cut-off value of CRP level on POD3 was $20.1 \mathrm{mg} / \mathrm{dl}$, with an AUC of 0.690 , a sensitivity of $58.3 \%$, and specificity of $83.7 \%$ (Figure $4 \mathrm{c}$ ).

Uni- and multivariate analysis for early predictive factors of POPF after DP for PC

In univariate logistic regression analysis, the POPF after DP for PC was significantly associated with the pancreatic to muscle SIR on $\mathrm{T}_{1}$-w MRI, D-Amy level on POD3, CRP level on POD3, and heart rate on POD3.

A multivariate logistic regression analysis revealed that pancreas-to-muscle SIR on $T_{1}-W$ MRI $(>1.37, p=$ 0.02; odds ratio [OR] = 17.08; 95\% confidence interval [Cl]: 1.64 - 598.16), D-Amy level on POD3 (>1200, $p$ $=0.02 ; \mathrm{OR}=20.00 ; 95 \% \mathrm{Cl}: 1.73-563.83)$, and heart rate on POD3 (>100bpm, $\mathrm{p}=0.02 ; \mathrm{OR}=15.33 ; 95 \%$ Cl: 1.53 - 258.45) were independent early predictive factor of POPF after DP for PC (Table 3). 


\section{Discussion}

POPF is the most serious complication of pancreatic surgery that leads to secondary complications. In this study, patients with POPF showed a significant increase in both hospital days and mortality. Additionally, POPF caused a delay in starting of postoperative treatment. The time required for definitive diagnosis for POPF may be closely related to these problems. In this study, the median time for POPF diagnosis was 9 days (range, 7-25), making early diagnosis difficult with routine postoperative examination. Therefore, detailed postoperative examination and early intervention based on predictive factors are necessary in DP for PC. In this study, we identified three early predictive factors for POPF; i) pancreas-to-muscle SIR on $T_{1}-\mathrm{W}$ MRI $>1.37$, ii) D-Amy level on POD3 $>1200 \mathrm{U} / \mathrm{L}$, and iii) heart rate on POD3 >100bpm.

In previous studies, various predictive factors for POPF after DP have been reported [11-31]. In particular, the pancreatic texture, the so-called 'soft pancreas,' is commonly recognized as one of the typical predictive factors. However, the problem is that the pancreatic texture is a very subjective factor and cannot be quantified. To solve this problem, we previously investigated the correlation between preoperative pancreatic MRI features and the histopathological features of pancreatic surgical specimens [33]. We found that the pancreas-to-muscle SIR on $\mathrm{T}_{1}-\mathrm{w}$ MRI had a significantly negative correlation with the pancreatic fibrosis grade. This is because normal pancreatic parenchyma exhibits hyperintensity on $\mathrm{T}_{1}-\mathrm{W} \mathrm{MRI}$, as pancreatic juice is rich in glycoproteins, and the endoplasmic reticulum within the pancreatic cells contributes to the $\mathrm{T} 1$ shortening effect. However, the signal intensity gradually decreases with progression of pancreatic atrophy, fibrosis, interstitial edema, or fat deposition [36, 37].

In another study [34], we reported that the frequency of POPF after pancreaticoduodenectomy (PD) was significantly higher in patients with low pancreatic fibrosis grade than in those with high grade. Based on these findings, we made a hypothesis that the pancreas-to-muscle SIR on $T_{1}-w$ MRI might be a potential imaging biomarker for predicting POPF reflecting pancreatic fibrosis. This study also showed that the pancreas-to-muscle SIR on $\mathrm{T}_{1}$-w MRI was significantly associated with POPF after DP for PC. This result is considered to be credible because the cut-off value for the POPF prediction calculated ROC analysis in this study (1.37) was close to that reported in our previous study (1.41).

The postoperative D-Amy level is also one of the well-established early predictors of POPF. Therefore, the definition of POPF according to the ISGPF offered the standard diagnosis according to the D-Amy level. The D-Amy level in the ISGPF were commonly measured on POD3. Some studies [29-31] have reported the D-Amy level on POD3 in predicting POPF. However, various D-Amy level on POD3 cut-off values have been proposed. Noji et al [29] were first to reveal that the D-Amy level on POD3 is the predictive factor of POPF after PD. They also showed that D-Amy level on POD3 $>3000 \mathrm{U} / \mathrm{L}$ was the best cut-off value, and the D-Amy level on POD3 was more useful than D-Amy level on POD1. Kanda et al [30] mentioned that the D-Amy level on POD3 was independently associated with POPF after DP, they also stated that the best cut-off value of D-Amy on POD3 was >1918 U/L. Fukami et al [31] showed that the best cut-off value of D-Amy on POD3 was >1044 U/L. They also revealed that the D-Amy on POD3 was early predictive factor 
of POPF after both PD and DP, and that that cut-off value of D-Amy on POD3 after DP (>3506U/L) tended to be higher than after PD (>713 U/L). In our study, similar results were shown for D-Amy level in early predicting POPF after DP. However, the best cut-off value in our study ( $>1200 \mathrm{U} / \mathrm{L})$ was slightly lower than that in the previous studies. This may be the result of our analysis being limited to pancreatic cancer cases. Since DP does not include pancreaticoenteral anastomosis, POPF after DP is less likely to have more serious complications than that after PD. Thus, in DP cases, it may be clinically appropriate to set the cut-off value higher in order to increase the positive predictive value.

This study had some limitations. This retrospectively designed study was undertaken at a single institution, and involved a small number of study patients. The relatively small sample size may have caused a selection bias. This limitation should be considered when evaluating our study results. A prospective, multi-centered study is needed involving a larger number of patients in the future.

\section{Conclusions}

Our results suggest that pancreas-to-muscle SIR on preoperative $\mathrm{T}_{1}$-weighted MRI, D-Amy level and heart rate on POD3 were significantly correlated with POPF after DP for PC. These objective parameters could be early predictive factors for POPF. Postoperative management based on these predictive factors may contribute to shortened hospital stay and smooth introduction to postoperative treatment.

\section{Abbreviations}

DP: distal pancreatectomy

PC: pancreatic cancer

POPF: postoperative pancreatic fistula

BMI: body mass index

JSHBPS: Japanese Society of Hepato-Biliary-Pancreatic Surgery

CEA: carcinoembryonic antigen

CA19-9: carbohydrate antigen 19-9

MRI: magnetic resonance imaging

D-Amy: drainage fluid amylase

S-Amy: serum amylase

WBC: white blood cells 
CRP: C-reactive protein

POD: postoperative day

SIR on T1-w MRI: signal intensity ratio on $\mathrm{T}_{1}$-weighted MRI

ISGPF: International Group of Pancreatic Fistula

CT: computed tomography

US: ultra-sonography

ROC: receiver operating characteristic

AUC: area under the curve

OR: odds ratio

Cl: confidence interval

\section{Declarations}

Ethics approval and consent to participate: The present study was conducted in accordance with the World Medical Association Declaration of Helsinki and was approved by the Ethics Committee of Gifu University (approval number '2021-26'). As this study was a retrospective study and did not include any potentially identifiable patient data, informed consent was not obtained from the enrolled patients. This retrospective study was approved by our Institutional Review Board.

Consent for publication: Not applicable.

Availability of data and materials: The datasets used during this study are available from the corresponding author upon reasonable request.

Competing interests: K. Yoshida has received honoraria for lectures from Chugai Pharmaceutical Co., Ltd., Taiho Pharmaceutical Co., Ltd., Takeda Pharmaceutical Co., Ltd., Eli Lilly and Company, Daiichi Sankyo Co., Ltd., Ono Pharmaceutical Co., Ltd., Merck Serono Co., Ltd., Novartis Pharma K.K., and Sanofi K.K., and research funding from Ajinomoto Pharmaceutical Co., Ltd., Takeda Pharmaceutical Co., Ltd., Chugai Pharmaceutical Co., Ltd., Daiichi Sankyo Co., Ltd., Taiho Pharmaceutical Co., Ono Pharmaceutical Co., and Yakult Honsha Co., Ltd., outside the submitted work.

T. Takahashi received honoraria for lectures from Takeda Pharmaceutical Co., Ltd. The remaining authors declare that they have no conflicts of interest.

Funding: None declared 
Authors' contributions: MF conceived the study concept and planned the design as the principal investigator. MF interpreted the results and wrote the manuscript draft.

$\mathrm{KM}, \mathrm{TH}$, and $\mathrm{KY}$ revised the manuscript draft through adding intellectual content and providing critical advice. MF, KM, TH, RY, YT, NO, NM, TT, and KY obtained the data and provided critical comments to improve the manuscript and gave final approval for submission.

Acknowledgements: The authors thank the medical staff of the Department of Gastroenterological Surgery at Gifu University Hospital for their participation in this study. We could not have completed this study without their diligence and support. We would also like to thank Editage (www.editage.jp) for English language editing.

\section{Authors' information:}

Department of Gastroenterological Surgery, Gifu University Hospital, 1-1 Yanagido, Gifu City, Gifu 5011194, Japan

\section{References}

1. Hirano S, Kondo S, Hara T, Ambo Y, Tanaka E, Shichinohe T, et al. Distal pancreatectomy with en bloc celiac axis resection for locally advanced pancreatic body cancer: long-term results. Ann Surg. 2007;246:46-51. https://doi.org/10.1097/01.sla.0000258608.52615.5a

2. McPhee JT, Hill JS, Whalen GF, Zayaruzny M, Litwin DE, Sullivan ME, et al. Perioperative mortality for pancreatectomy: a national perspective. Ann Surg. 2007;246:246-53.

https://doi.org/10.1097/01.sla.0000259993.17350.3a

3. Sledzianowski JF, Duffas JP, Muscari F, Suc B, Fourtanier F. Risk factors for mortality and intraabdominal morbidity after distal pancreatectomy. Surgery. 2005;137:180-5. https://doi.org/10.1016/j.surg.2004.06.063

4. Goh BK, Tan YM, Chung YF, Cheow PC, Ong HS, Chan WH, et al. Critical appraisal of 232 consecutive distal pancreatectomies with emphasis on risk factors, outcome, and management of the postoperative pancreatic fistula: a 21-year experience at a single institution. Arch Surg. 2008;143:956-65. https://doi.org/10.1001/archsurg.143.10.956

5. Shimada K, Sakamoto Y, Sano T, Kosuge T. Prognostic factors after distal pancreatectomy with extended lymphadenectomy for invasive pancreatic adenocarcinoma of the body and tail. Surgery. 2006;139:288-95. https://doi.org/10.1016/j.surg.2005.08.004

6. Lillemoe KD, Kaushal S, Cameron JL, Sohn TA, Pitt HA, Yeo CJ. Distal pancreatectomy: indications and outcomes in 235 patients. Ann Surg. 1999;229:693-8; discussion 698. https://doi.org/10.1097/00000658-199905000-00012

7. Fujino Y. Perioperative management of distal pancreatectomy. World J Gastroenterol. 2015;21:31669. https://doi.org/10.3748/wjg.v21.i11.3166 
8. Sell NM, Pucci MJ, Gabale S, Leiby BE, Rosato EL, Winter JM, et al. The influence of transection site on the development of pancreatic fistula in patients undergoing distal pancreatectomy: a review of 294 consecutive cases. Surgery. 2015;157:1080-7. https://doi.org/10.1016/j.surg.2015.01.014

9. Glowka TR, von Websky M, Pantelis D, Manekeller S, Standop J, Kalff JC, et al. Risk factors for delayed gastric emptying following distal pancreatectomy. Langenbecks Arch Surg. 2016;401:1617. https://doi.org/10.1007/s00423-016-1374-7

10. National Comprehensive Cancer Network. the Clinical Practice Guidelines in Oncology. Pancreatic adenocarcinoma. version $1.2021 ; 2020$

11. Ridolfini MP, Alfieri S, Gourgiotis S, Di Miceli D, Rotondi F, Quero G, et al. Risk factors associated with pancreatic fistula after distal pancreatectomy, which technique of pancreatic stump closure is more beneficial? World J Gastroenterol. 2007;13:5096-100. https://doi.org/10.3748/wjg.v13.i38.5096

12. Pannegeon V, Pessaux P, Sauvanet A, Vullierme MP, Kianmanesh R, Belghiti J. Pancreatic fistula after distal pancreatectomy: predictive risk factors and value of conservative treatment. Arch Surg. 2006;141:1071-6; discussion 1076. https://doi.org/10.1001/archsurg.141.11.1071

13. Yoshioka R, Saiura A, Koga R, Seki M, Kishi Y, Morimura R, et al. Risk factors for clinical pancreatic fistula after distal pancreatectomy: analysis of consecutive 100 patients. World J Surg. 2010;34:121-5. https://doi.org/10.1007/s00268-009-0300-3

14. Distler M, Kersting S, Rückert F, Kross P, Saeger HD, Weitz J, et al. Chronic pancreatitis of the pancreatic remnant is an independent risk factor for pancreatic fistula after distal pancreatectomy. BMC Surg. 2014;14:54. https://doi.org/10.1186/1471-2482-14-54

15. Gomes RM, Doctor N. Three level risk assessment for pancreatic fistula formation after distal pancreatectomy with a strategy for prevention. Trop Gastroenterol. 2012;33:207-13. https://doi.org/10.7869/tg.2012.50

16. Soga K, Ochiai T, Sonoyama T, Inoue K, Ikoma H, Kikuchi S, et al. Risk factors for postoperative pancreatic fistula in distal pancreatectomy. Hepato-Gastroenterology. 2011;58:1372-6. https://doi.org/10.5754/hge09255

17. Kawabata Y, Nishi T, Tanaka T, Yano S, Tajima Y. Distal pancreatectomy utilizing a flexible stapler closure eliminates the risk of pancreas-related factors for postoperative pancreatic fistula. Eur Surg Res. 2013;50:71-9. https://doi.org/10.1159/000349977

18. Eguchi H, Nagano H, Tanemura M, Takeda Y, Marubashi S, Kobayashi S, et al. A thick pancreas is a risk factor for pancreatic fistula after a distal pancreatectomy: selection of the closure technique according to the thickness. Dig Surg. 2011;28:50-6. https://doi.org/10.1159/000322406

19. Sugimoto M, Gotohda N, Kato Y, Takahashi S, Kinoshita T, Shibasaki H, et al. Risk factor analysis and prevention of postoperative pancreatic fistula after distal pancreatectomy with stapler use. J HepatoBil Pancreat Sci. 2013;20:538-44. https://doi.org/10.1007/s00534-013-0596-0

20. Kah Heng CA, Salleh I, San TS, Ying F, Su-Ming T. Pancreatic fistula after distal pancreatectomy: incidence, risk factors and management. ANZ J Surg. 2010;80:619-23. https://doi.org/10.1111/j.1445-2197.2010.05337.x 
21. Makni A, Rebai W, Daghfouss A, Ayadi S, Fterich F, Chebbi F, et al. Risk factors associated with pancreatic fistula after distal pancreatectomy. Tunis Med. 2012;90:148-53

22. Sierzega M, Niekowal B, Kulig J, Popiela T. Nutritional status affects the rate of pancreatic fistula after distal pancreatectomy: a multivariate analysis of 132 patients. J Am Coll Surg. 2007;205:52-9. https://doi.org/10.1016/j.jamcollsurg.2007.02.077

23. Kawai M, Tani M, Yamaue $H$. Transection using bipolar scissors reduces pancreatic fistula after distal pancreatectomy. J Hepato-Bil Pancreat Surg. 2008;15:366-72. https://doi.org/10.1007/s00534-008-1330-1

24. Sato N, Mori Y, Minagawa N, Tamura T, Shibao K, Higure A, et al. Rapid postoperative reduction in prognostic nutrition index is associated with the development of pancreatic fistula following distal pancreatectomy. Pancreatology. 2014;14:216-20. https://doi.org/10.1016/j.pan.2014.02.006

25. Subhedar PD, Patel SH, Kneuertz PJ, Maithel SK, Staley CA, Sarmiento JM, et al. Risk factors for pancreatic fistula after stapled gland transection. Am Surg. 2011;77:965-70. https://doi.org/10.1177/000313481107700811

26. Mendoza AS 3rd, Han HS, Ahn S, Yoon YS, Cho JY, Choi Y. Predictive factors associated with postoperative pancreatic fistula after laparoscopic distal pancreatectomy: a 10-year single-institution experience. Surg Endosc. 2016;30:649-56. https://doi.org/10.1007/s00464-015-4255-1

27. Okano K, Oshima M, Kakinoki K, Yamamoto N, Akamoto S, Yachida S, et al. Pancreatic thickness as a predictive factor for postoperative pancreatic fistula after distal pancreatectomy using an endopath stapler. Surg Today. 2013;43:141-7. https://doi.org/10.1007/s00595-012-0235-4

28. Frozanpor F, Albiin N, Linder S, Segersvärd R, Lundell L, Arnelo U. Impact of pancreatic gland volume on fistula formation after pancreatic tail resection. JOP. 2010;11:439-43

29. Noji T, Nakamura T, Ambo Y, Suzuki O, Nakamura F, Kishida A, et al. Clinically relevant pancreasrelated infectious complication after pancreaticoenteral anastomosis could be predicted by the parameters obtained on postoperative day 3. Pancreas. 2012;41:916-21. https://doi.org/10.1097/MPA.0b013e31823e7705

30. Kanda M, Fujii T, Takami H, Suenaga M, Inokawa Y, Yamada S, et al. Novel diagnostics for aggravating pancreatic fistulas at the acute phase after pancreatectomy. World J Gastroenterol. 2014;20:8535-44. https://doi.org/10.3748/wjg.v20.i26.8535

31. Fukami Y, Saito T, Osawa T, Hanazawa T, Kurahashi T, Kurahashi S, et al. Which is the best predictor of clinically relevant pancreatic fistula after pancreatectomy: drain fluid concentration or total amount of amylase? Ann Gastroenterol Surg. 2021;5:844-52. https://doi.org/10.1002/ags3.12471

32. Japan Pancreas Society. Classification of pancreatic carcinoma. 4th ed. Tokyo: Kanehara \& Co., Ltd.; 2017

33. Watanabe H, Kanematsu M, Tanaka K, Osada S, Tomita H, Hara A, et al. Fibrosis and postoperative fistula of the pancreas: correlation with MR imaging findings - preliminary results. Radiology. 2014;270:791-9. https://doi.org/10.1148/radiol.13131194 
34. Noda Y, Goshima S, Suzui N, Miyazaki T, Kajita K, Kawada H, et al. Pancreatic MRI associated with pancreatic fibrosis and postoperative fistula: comparison between pancreatic cancer and nonpancreatic cancer tissue. Clin Radiol. 2019;74:490.e1-490.e6.

https://doi.org/10.1016/j.crad.2019.02.013

35. Bassi C, Dervenis C, Butturini G, Fingerhut A, Yeo C, Izbicki J, et al. Postoperative pancreatic fistula: an international study group (ISGPF) definition. Surgery. 2005;138:8-13. https://doi.org/10.1016/j.surg.2005.05.001

36. Mitchell DG, Vinitski S, Saponaro S, Tasciyan T, Burk DL Jr, Rifkin MD. Liver and pancreas: improved spin-echo T1 contrast by shorter echo time and fat suppression at 1.5 T. Radiology. 1991;178:67-71. https://doi.org/10.1148/radiology.178.1.1984328

37. Winston CB, Mitchell DG, Outwater EK, Ehrlich SM. Pancreatic signal intensity on T1-weighted fat saturation MR images: clinical correlation. J Magn Reson Imaging. 1995;5:267-71. https://doi.org/10.1002/jmri.1880050307

\section{Tables}

Table 1 Comparison of clinical outcomes between patient with and without POPF after distal pancreatectomy

\begin{tabular}{|c|c|c|c|c|}
\hline & \multicolumn{2}{|c|}{ Patients with POPF $(n=12)$} & \multirow{2}{*}{$\begin{array}{l}\text { Patients without } \\
\text { POPF }(n=43) \\
-\end{array}$} & \multirow{2}{*}{$\begin{array}{l}\mathrm{p}- \\
\text { value } \\
-\end{array}$} \\
\hline Diagnosis days of POPF (day) & $9(7-25)$ & & & \\
\hline Grade of POPF" & & & & - \\
\hline Grade B & $10(83.3)$ & & - & \\
\hline Grade C & $2(16.7)$ & & - & \\
\hline \multirow[t]{2}{*}{ Treatment for POPF } & $\begin{array}{l}\text { QDrain replacement } \\
\text { and irrigation }\end{array}$ & $\begin{array}{l}9 \\
(75.0)\end{array}$ & - & - \\
\hline & $\begin{array}{l}\text { पEndoscopic } \\
\text { transgastric } \\
\text { drainage }\end{array}$ & $\begin{array}{l}3 \\
(25.0)\end{array}$ & & \\
\hline Postoperative death within 30 days & $2(16.7)$ & & $0(0.0)$ & $0.01^{\square}$ \\
\hline Hospital days (days) & $39(12-81)$ & & $14(10-20)$ & $<0.01^{\square}$ \\
\hline Postoperative adjuvant chemotherapy & $9(75.0)$ & & $34(79.1)$ & 0.76 \\
\hline $\begin{array}{l}\text { Period until the start of postoperative } \\
\text { adjuvant chemotherapy§ }\end{array}$ & $65(45-107)$ & & $40.5(22-134)$ & $<0.01^{\square}$ \\
\hline
\end{tabular}

Data are expressed as median (range) or number of patients (percentage) 
POPF: postoperative pancreatic fistula

9: International Study Group (ISGPS) definition and grading of POPF as follow: Grade B, symptomatic fistula requiring therapeutic intervention such as antibiotics and percutaneous drainage; Grade $C$, symptomatic fistula associated with a severe general condition of patients, sepsis, and multiorgan failure requiring aggressive treatment in the intensive care unit and surgical intervention.

$\S:$ Period until the start of postoperative adjuvant chemotherapy was calculated from the date of the surgery.

Table 2 Comparison of pre, intra-, and post-operative status between patient with and without POPF after distal pancreatectomy 


\begin{tabular}{|c|c|c|c|c|}
\hline & & $\begin{array}{l}\text { Patients with } \\
\text { POPF }\end{array}$ & $\begin{array}{l}\text { Patients without } \\
\text { POPF }\end{array}$ & $\begin{array}{l}\mathrm{p}- \\
\text { value }\end{array}$ \\
\hline & & $(n=12)$ & $(n=43)$ & \\
\hline Pre-operative & Age (years) & $68.5(63-82)$ & $73(42-84)$ & 0.94 \\
\hline & Sex & & & 0.99 \\
\hline & Male & $7(58.3)$ & $25(58.1)$ & \\
\hline & Female & $5(41.7)$ & $18(41.9)$ & \\
\hline & $\mathrm{BMI}\left(\mathrm{kg} / \mathrm{m}^{2}\right)$ & $23.6(20.1-26.3)$ & $21.8(16.2-31.9)$ & 0.18 \\
\hline & Diabetes mellitus & $3(25.0)$ & $17(39.5)$ & 0.35 \\
\hline & $\begin{array}{l}\text { Serum albumin level } \\
(\mathrm{g} / \mathrm{dl})\end{array}$ & $4.1(3.3-4.4)$ & $4.1(3.0-4.9)$ & 0.20 \\
\hline & CEA level (ng/ml) & $3.6(1.4-9.0)$ & $2.9(0.7-72.4)$ & 0.25 \\
\hline & CA19-9 level (ng/ml) & 109 (14.9-9528) & $60.1(0.1-3333)$ & 0.43 \\
\hline & $\begin{array}{l}\text { Preoperative } \\
\text { chemotherapy }\end{array}$ & $3(25.0)$ & $16(37.2)$ & 0.49 \\
\hline & Tumor size (mm) & $20.5(14-40)$ & $25(4-70)$ & 0.23 \\
\hline & Location & & & 0.07 \\
\hline & $\mathrm{Pb}$ & $5(41.7)$ & $30(69.8)$ & \\
\hline & $\mathrm{Pt}$ & $7(58.3)$ & $13(30.2)$ & \\
\hline & Pancreas-to-muscle SIR & $1.58(1.25-1.86)$ & $1.24(0.82-1.75)$ & $<0.01^{\square}$ \\
\hline & on $\mathrm{T}_{1}$-w MRI & & & \\
\hline Intra- & Operative time (min) & $270(195-473)$ & $286(143-564)$ & 0.61 \\
\hline & Blood loss (ml) & $185(50-1840)$ & $385(0-1840)$ & 0.27 \\
\hline & Surgical procedure & & & 0.92 \\
\hline & Open & $11(91.7)$ & $39(90.7)$ & \\
\hline & Laparoscopic & $1(8.3)$ & $4(9.3)$ & \\
\hline & Resection procedure & & & 0.50 \\
\hline & Hand-sewn & $4(33.3)$ & $19(44.2)$ & \\
\hline & Stapler & $8(66.7)$ & $24(55.8)$ & \\
\hline & Pancreas texture & & & 0.92 \\
\hline & Soft & $8(66.7)$ & $28(65.1)$ & \\
\hline
\end{tabular}




\begin{tabular}{|c|c|c|c|c|}
\hline & Hard & $4(33.3)$ & 15 (34.9) & \\
\hline & Pancreas thickness $(\mathrm{mm})$ & $11(9-14)$ & $11(3-24)$ & 0.67 \\
\hline \multirow{18}{*}{$\begin{array}{l}\text { Post- } \\
\text { operative }\end{array}$} & \multicolumn{4}{|l|}{ D-Amy level (U/L) } \\
\hline & POD1 & 3091 (108-31196) & $1019(42-12351)$ & 0.09 \\
\hline & POD3 & $1244(42-16515)$ & $231(41-5153)$ & $0.02^{\square}$ \\
\hline & \multicolumn{4}{|l|}{ S-Amy level (U/L) } \\
\hline & POD1 & $105(47-610)$ & 170 (35-979) & 0.15 \\
\hline & POD3 & $33(11-223)$ & $48(18-663)$ & $0.04^{\square}$ \\
\hline & \multicolumn{4}{|l|}{ WBC $\left(\times 10^{3} / \mu \mathrm{l}\right)$} \\
\hline & POD1 & $13.25(9.87-26.49)$ & $11.40(5.34-18.16)$ & 0.08 \\
\hline & POD3 & $13.30(5.9-21.71)$ & $11.63(6.4-23.9)$ & 0.33 \\
\hline & \multicolumn{4}{|l|}{ CRP (mg/dl) } \\
\hline & POD1 & $9.68(4.02-14.3)$ & $8.85(0.18-15.14)$ & 0.16 \\
\hline & POD3 & $20.6(10.7-27.36)$ & $14.40(2.13-26.52)$ & $0.046^{\square}$ \\
\hline & \multicolumn{4}{|l|}{ Body temperature $\left({ }^{\circ} \mathrm{C}\right)$} \\
\hline & POD1 & $38.1(37.2-39.4)$ & $38.0(37.3-39.3)$ & 0.69 \\
\hline & POD3 & $37.1(36.1-38.9)$ & $37.4(36.6-39.4)$ & 0.28 \\
\hline & \multicolumn{4}{|l|}{ Heart rate (bpm) } \\
\hline & POD1 & $97(82-142)$ & $92(61-117)$ & 0.21 \\
\hline & POD3 & $94(78-109)$ & $83(60-119)$ & $0.03^{\square}$ \\
\hline
\end{tabular}

Data are expressed as median (range) or number of patients

POPF: postoperative pancreatic fistula

BMl: body mass index

CEA: Carcinoembryonic antigen level, normal upper limit at $5 \mathrm{ng} / \mathrm{ml}$

CA19-9: Carbohydrate antigen 19-9 level, normal upper limit at 37ng/ml

Pancreas-to-muscle SIR on $\mathrm{T}_{1}$-w MRI: The pancreas-to-muscle signal intensity ratio on unenhanced $\mathrm{T}_{1^{-}}$ weigthed magnetic resonance imaging 
S-Amy: Serum amylase

D-Amy: Drainage fluid amylase

POD: postoperative day

WBC: white blood cell count

CRP: c-reactive protein

$\rrbracket: p<0.05$

Table 3 Uni- and multivariate predictive factors of POPF after DP for PC 


\begin{tabular}{|c|c|c|c|c|c|c|c|c|}
\hline & & $\mathrm{n}(\%)$ & Univa & & & Mult & iate & \\
\hline & & & OR & $95 \% \mathrm{Cl}$ & $\begin{array}{l}\mathrm{p}- \\
\text { value }\end{array}$ & OR & $95 \% \mathrm{Cl}$ & $\begin{array}{l}p \text { - } \\
\text { value }\end{array}$ \\
\hline Pre- & Age (years) & & & $0.12-$ & 0.25 & & & \\
\hline & $>70$ & 31 & 0.47 & & & & & \\
\hline & $<70$ & 24 & 1 & & & & & \\
\hline & Sex & & & $0.28-$ & 0.99 & & & \\
\hline & Male & 32 & 1.01 & & & & & \\
\hline & Female & 23 & 1 & & & & & \\
\hline & $\mathrm{BMI}\left(\mathrm{kg} / \mathrm{m}^{2}\right)$ & & & $\begin{array}{l}0.60- \\
970\end{array}$ & 0.21 & & & \\
\hline & $>24$ & 16 & 2.42 & & & & & \\
\hline & $<24$ & 39 & 1 & & & & & \\
\hline & Diabetes mellitus & 20 & 0.51 & $0.10-$ & 0.34 & & & \\
\hline & yes & 35 & 1 & & & & & \\
\hline & no & & & & & & & \\
\hline & $\begin{array}{l}\text { Serum albumin level } \\
(\mathrm{mg} / \mathrm{dl})\end{array}$ & & & $\begin{array}{l}0.05- \\
1.26\end{array}$ & 0.09 & & & \\
\hline & $>3.6$ & & & & & & & \\
\hline & $<3.6$ & 40 & $0 . \angle 0$ & & & & & \\
\hline & & 9 & 1 & & & & & \\
\hline & CEA level (ng/ml) & & 1.71 & $0.32-$ & 0.50 & & & \\
\hline & $>5.0$ & 10 & 1 & & & & & \\
\hline & $<5.0$ & 45 & & & & & & \\
\hline & CA19-9 level (ng/ml) & & 1.78 & $0.45-$ & 0.42 & & & \\
\hline & $>37.0$ & 36 & 1 & & & & & \\
\hline & $<37.0$ & 19 & & & & & & \\
\hline & $\begin{array}{l}\text { Preoperative } \\
\text { chemotherapy }\end{array}$ & & & $\begin{array}{l}0.11- \\
2.21\end{array}$ & 0.42 & & & \\
\hline & yes & 19 & 0.56 & & & & & \\
\hline & 110 & 36 & 1 & & & & & \\
\hline & Tumor size $(\mathrm{mm})$ & & & $\begin{array}{l}0.16- \\
2.19\end{array}$ & 0.43 & & & \\
\hline
\end{tabular}




\begin{tabular}{|c|c|c|c|c|c|c|c|c|}
\hline & $>20$ & 33 & 0.59 & & & & & \\
\hline & $<20$ & 22 & 1 & & & & & \\
\hline & Location & & 3.23 & $0.88-$ & 0.08 & & & \\
\hline & $\mathrm{Pb}$ & 35 & 1 & & & & & \\
\hline & $\mathrm{Pt}$ & 20 & & & & & & \\
\hline & $\begin{array}{l}\text { Pancreas-to-muscle SIR } \\
\text { on } \mathrm{T}_{1} \text {-w MRI }\end{array}$ & & & $\begin{array}{l}2.90- \\
352.15\end{array}$ & $<0.01^{\square}$ & & $\begin{array}{l}1.64- \\
598.16\end{array}$ & $0.02^{\square}$ \\
\hline & $>1.37$ & 21 & 18.0 & & & 17.08 & & \\
\hline & $<1.37$ & 34 & 1 & & & 1 & & \\
\hline Intra- & Operative time (min) & & 0.40 & $0.08-$ & 0.20 & & & \\
\hline & $>300$ & 22 & 1 & & & & & \\
\hline & $<300$ & 33 & & & & & & \\
\hline & Blood loss (ml) & & & $0.07-$ & 0.12 & & & \\
\hline & $>400$ & 24 & 0.33 & & & & & \\
\hline & $<400$ & 31 & 1 & & & & & \\
\hline & Surgical procedure & & & $\begin{array}{l}0.15- \\
0327\end{array}$ & 0.92 & & & \\
\hline & Open & 50 & 1.13 & & & & & \\
\hline & Laparoscopic & 5 & 1 & & & & & \\
\hline & Resection procedure & 23 & & $0.15-$ & 0.50 & & & \\
\hline & Hand-sewn & 32 & 0.63 & & & & & \\
\hline & Stapler & & 1 & & & & & \\
\hline & Pancreas texture & & & $\begin{array}{l}0.29- \\
455\end{array}$ & 0.92 & & & \\
\hline & Soft & 36 & 1.07 & & & & & \\
\hline & Hard & 19 & 1 & & & & & \\
\hline & $\begin{array}{l}\text { Pancreas thickness } \\
(\mathrm{mm})\end{array}$ & & & $\begin{array}{l}0.82- \\
25.30\end{array}$ & 0.09 & & & \\
\hline & $>12$ & & 0.27 & & & & & \\
\hline & $<12$ & 35 & 1 & & & & & \\
\hline $\begin{array}{l}\text { Post- } \\
\text { operative }\end{array}$ & $\begin{array}{l}\text { D-Amy level (U/L) - } \\
\text { POD3 }\end{array}$ & 13 & 8.63 & $\begin{array}{l}2.13- \\
39.16\end{array}$ & $<0.01^{\square}$ & 20.00 & $\begin{array}{l}1.73- \\
563.83\end{array}$ & $0.02^{\square}$ \\
\hline & $>1200$ & 42 & 1 & & & 1 & & \\
\hline
\end{tabular}




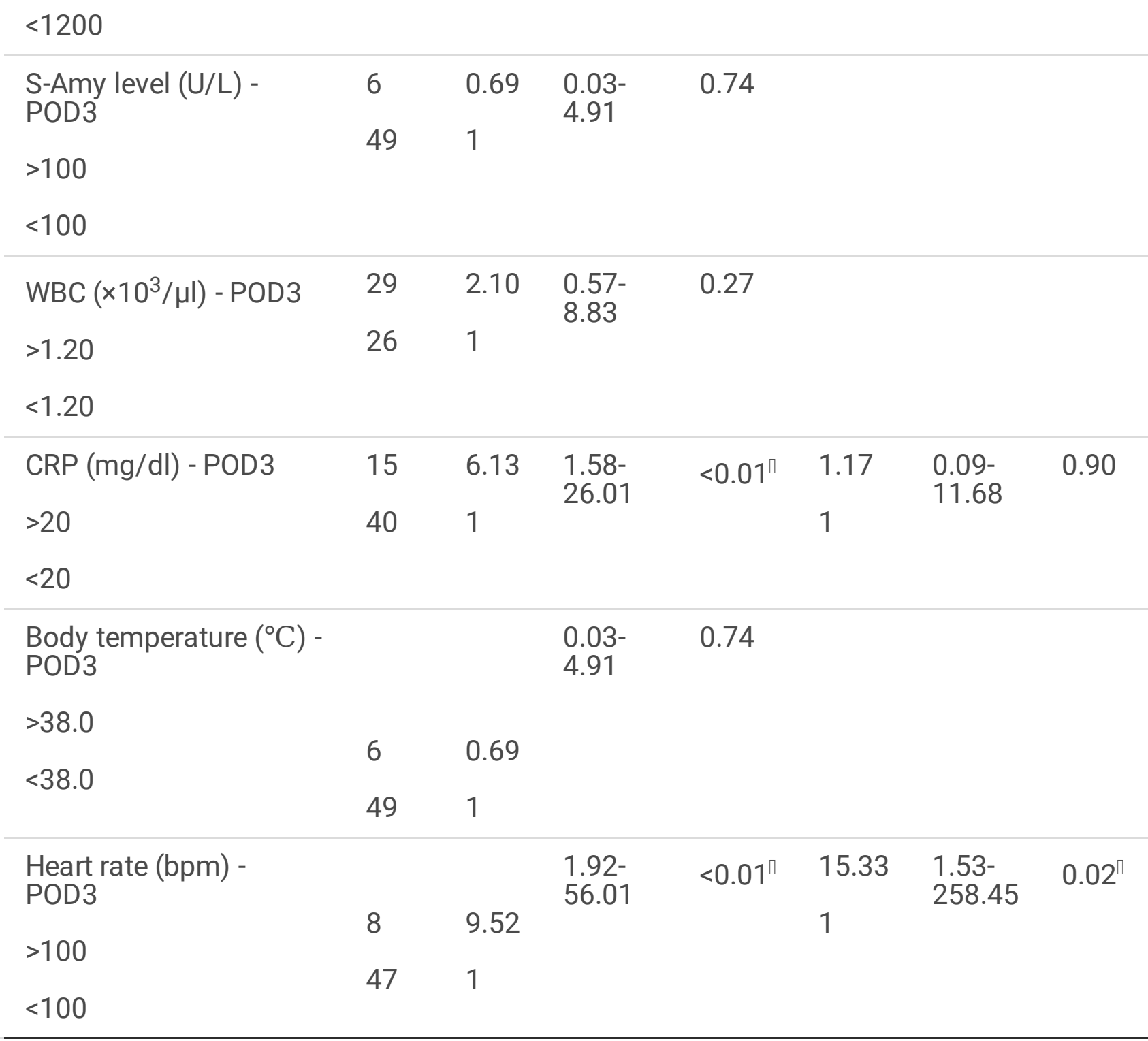

POPF: postoperative pancreatic fistula

OR: odds ratio

95\%Cl: 95\% confidence interval

BMl: body mass index

CEA: Carcinoembryonic antigen level, normal upper limit at $5 \mathrm{ng} / \mathrm{ml}$

CA19-9: Carbohydrate antigen 19-9 level, normal upper limit at 37ng/ml

Pancreas-to-muscle SIR on $T_{1}$-w MRI: The pancreas-to-muscle signal intensity ratio on unenhanced $\mathrm{T}_{1}{ }^{-}$ weigthed magnetic resonance imaging

D-Amy: Drainage fluid amylase

S-Amy: Serum amylase 
POD: postoperative day

WBC: white blood cell count

CRP: c-reactive protein

刃: $p<0.05$

Figures

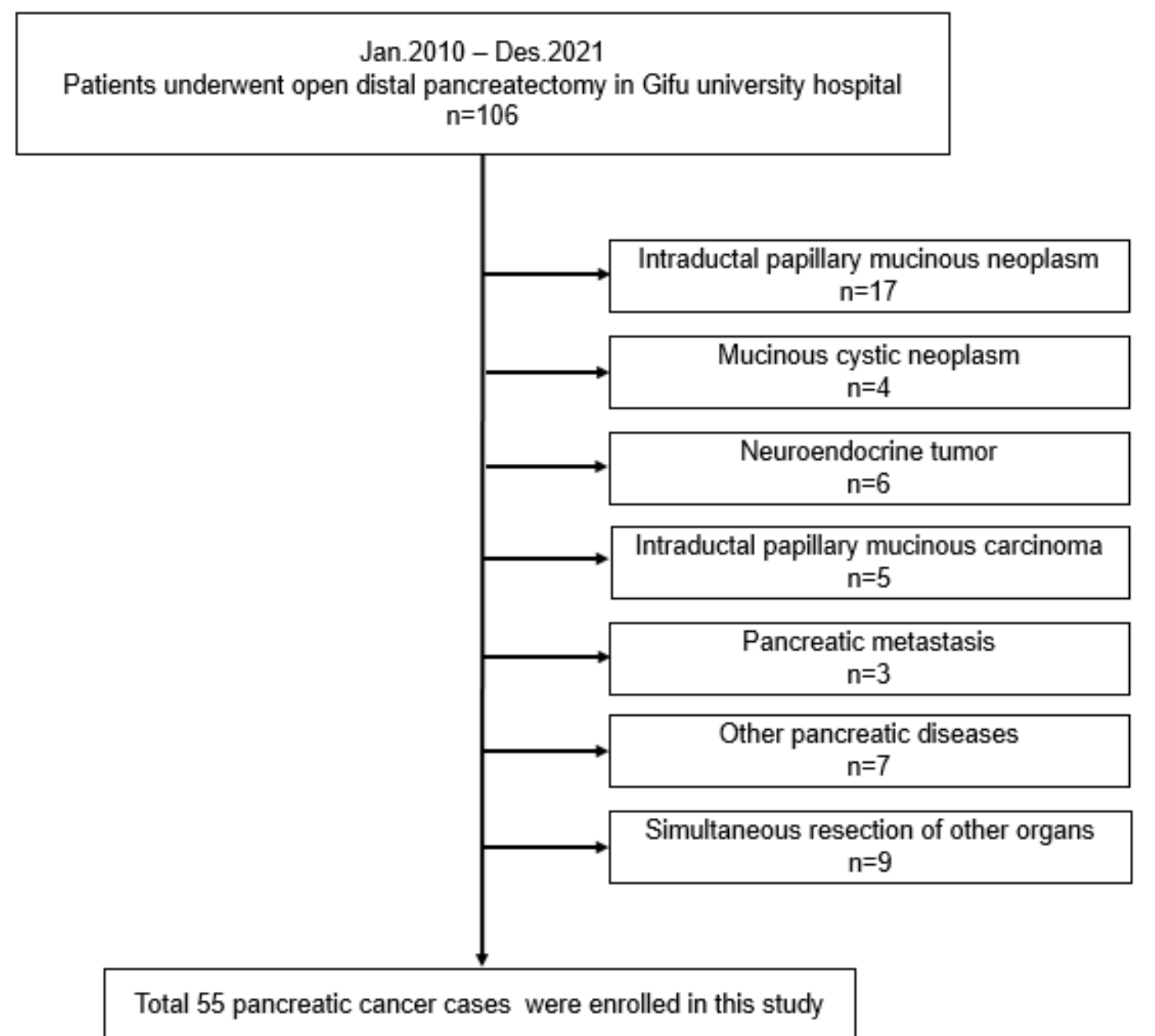

Fig.1

\section{Figure 1}

Exclusion criteria 


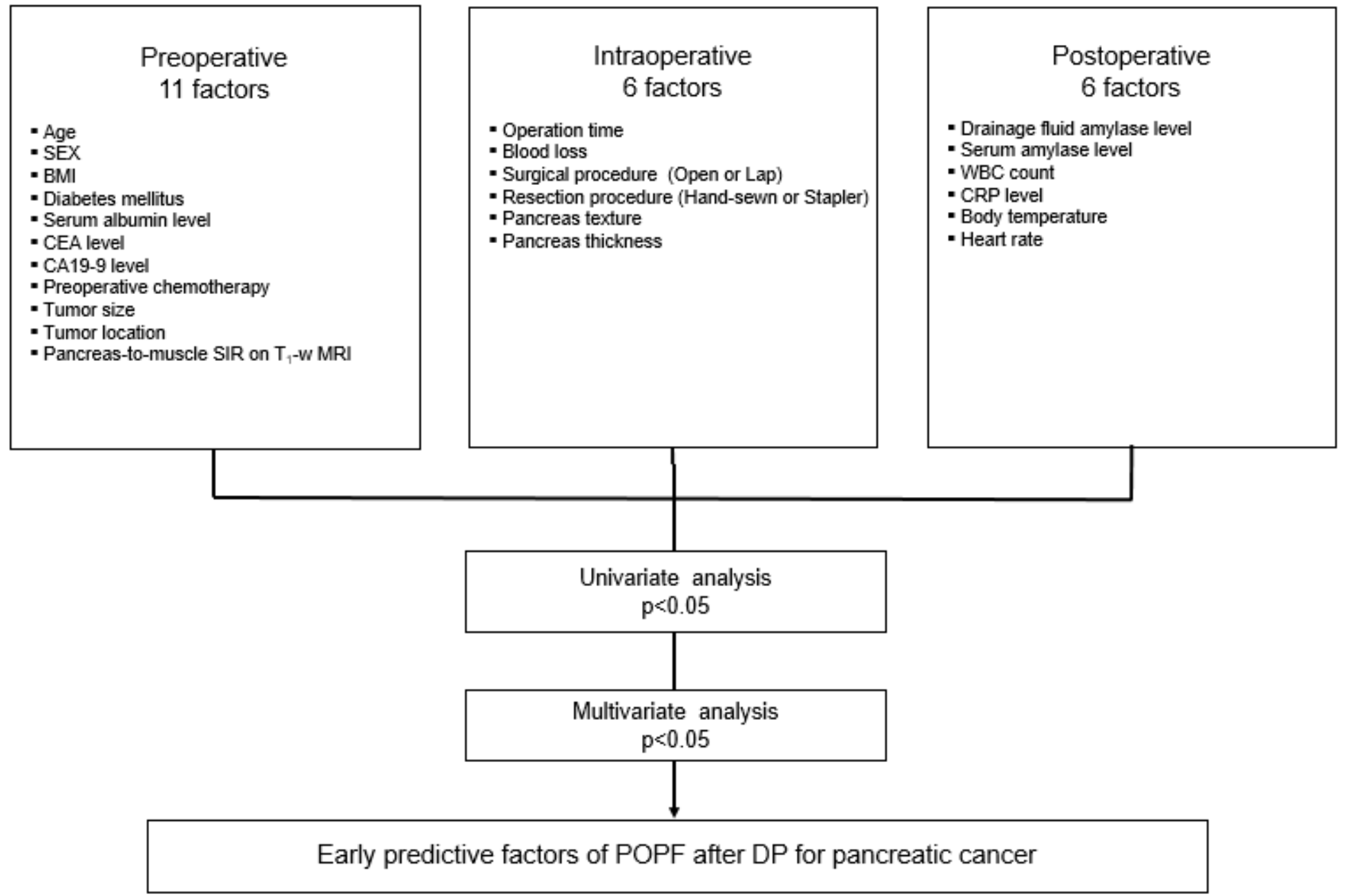

Fig.2

\section{Figure 2}

Analysis flow chart for identifying predictive factors for postoperative pancreatic fistula (POPF) after distal pancreatectomy (DP) for pancreatic cancer 

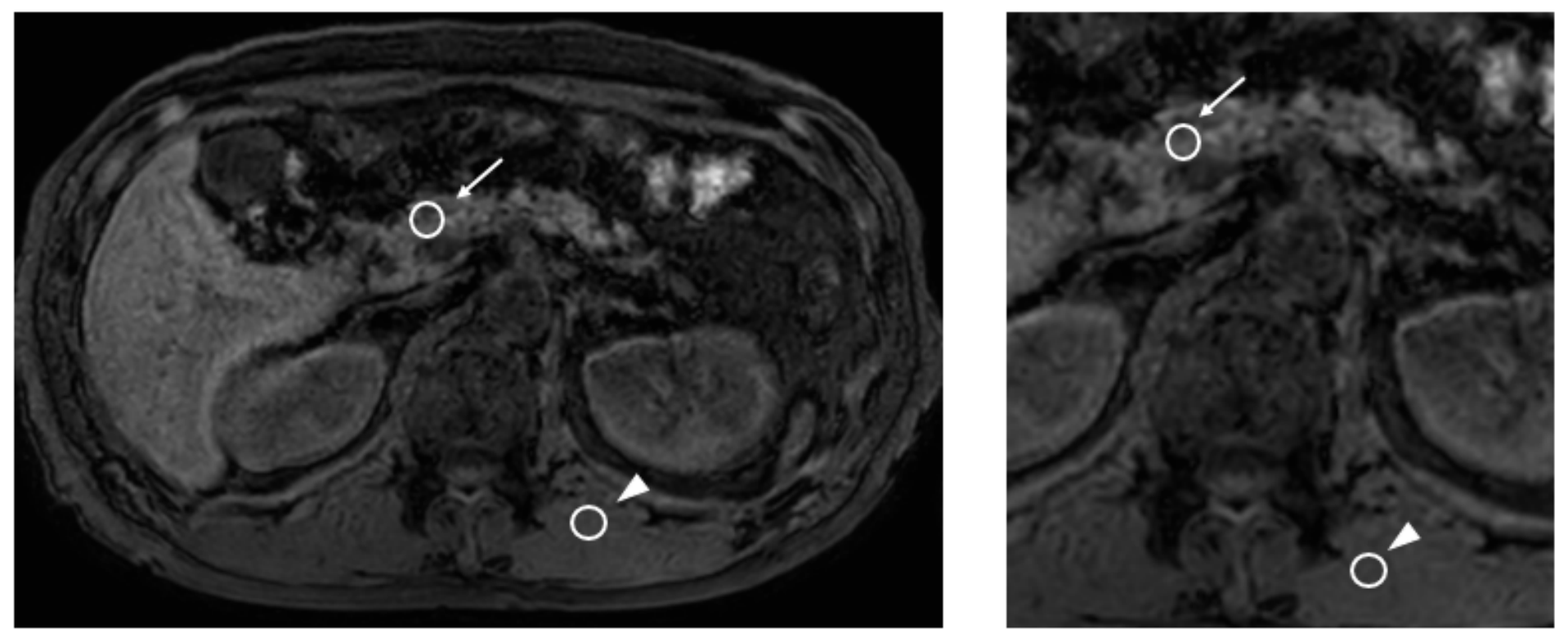

Fig.3

\section{Figure 3}

The pancreas-to-muscle signal intensity ratio on fat-suppressed axial $\mathrm{T}_{1}$-weighted MRI was calculated by [Signal intensity of the pancreatic parenchyma] (arrow) / [Signal intensity of the paraspinal muscle] (arrowhead). 
(a)Pancreas-to-muscle SIR on $\mathrm{T}_{1}$-weighted MRI

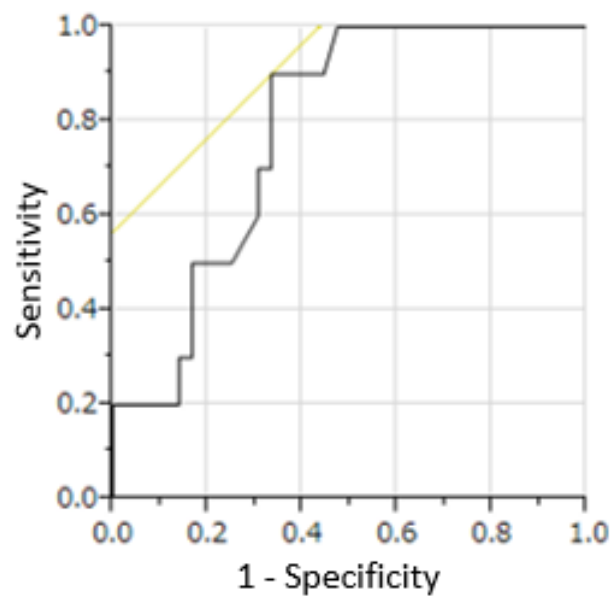

(c) CRP - POD3

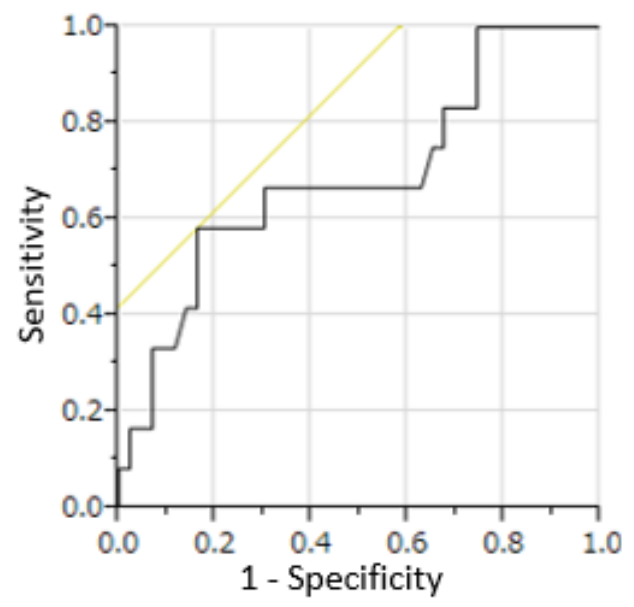

(b) D-Amy - POD3

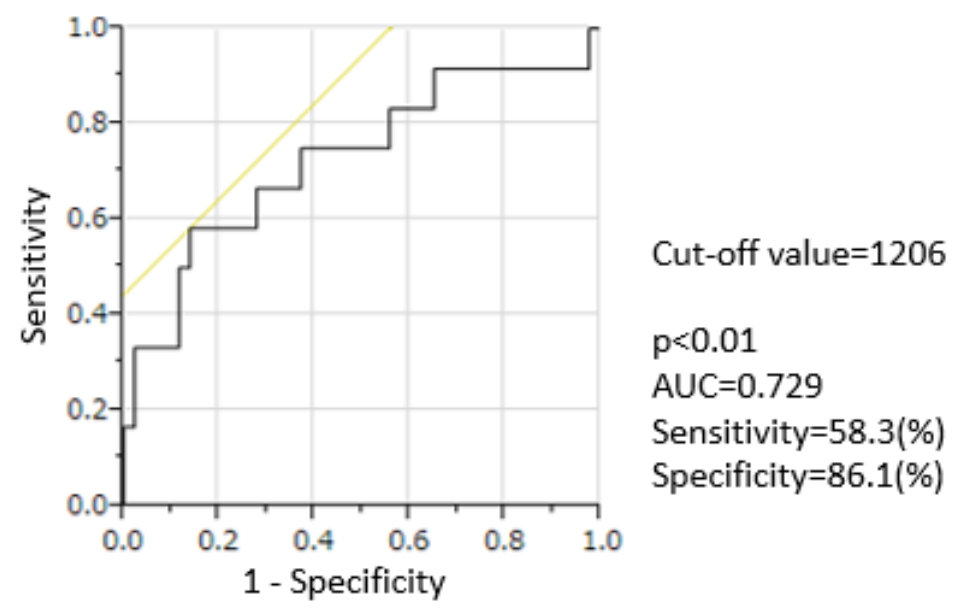

Cut-off value $=20.1$

$\mathrm{P}=0.03$

AUC $=0.690$

Sensitivity $=58.3(\%)$

Specificity $=83.7(\%)$

Fig.4

Figure 4

Receiver operating characteristics (ROC) curve analysis of pancreas-to-muscle SIR on $\mathrm{T}_{1}$-weighted MRI, DAmy level on POD3, and CRP level on POD3 for discriminating to POPF. 